\title{
The business case is a basket case: an introduction
}

Oh, I hear you: 'Barnett, what are you trying to pull here? Isn't this just a collection of reprints?' Sure, the bulk of the book consists of reprints. But if you'll allow me to explain, there's much more to it than that. And besides, there's merit in reprints.

In this book, I put forth a critical view of the business case for corporate social responsibility. Management scholars have claimed for decades that firms can 'do well by doing good' and firms have backed this claim. Unlike most things academic, the idea has caught fire beyond the ivory tower. Today it's hard to even imagine a firm declaring that society is none of its business. You don't tend to hear a CEO saying, 'Yes, we harpoon some whales and kick a puppy or two along the way, but come on, we have to make a buck somehow!' Firms instead spend their limited resources engaging in various good deeds and broadcasting how doing so benefits both society and their firms. For example, Target donates five percent of its profits to communities and proclaims prominently on its corporate website: 'We believe diversity and inclusivity make teams and Target better. And we'll live that belief as champions of a more inclusive society by creating a diverse and inclusive work environment, cultivating an inclusive guest experience, and fostering equality in society.'

That said, revealed corporate behaviors all too often fall short of the rhetoric of widespread corporate social responsibility. With the same ease that I can find a press release or annual report from just about any firm declaring that it is a paragon of social virtue, I can also uncover not just assertions but settlements and convictions for irresponsible and often illegal corporate behaviors that harm society. Look, whales really are being harpooned and puppies really are getting kicked in the pursuit of profit. Just watch a few Greenpeace or ASPCA videos (on an empty stomach). We people and our planet also suffer at the hands of ongoing corporate irresponsibility and misconduct, from bribery and bid rigging, to catastrophic climate change.

Despite decades of academic and practitioner support for the assertion that firms do best by bettering society, firms still do many bad things that cause substantial harm to society. Yet these misdeeds may have few consequences for the offending firms; in fact, firms that do bad things can still prosper. Chevron, De Beers, Exxon, Nestlé, Pfizer, and Volkswagen are a few amongst a too-long list of highly profitable firms that paid fines and settlements related to some truly horrible actions. Also troubling for the business case, firms that do good things may see little or no reward for their efforts; even the most socially responsible of firms remains vulnerable to bankruptcy.

Clearly the relationship between doing good and doing well is imperfect. My aim in this book is to shine a light on these imperfections, argue that they exist because there are limits to stakeholder influence, and offer insights on what to do in light of these limits if we really want business to be more responsible to and for society. How lucky is it, then, that I've been publishing studies in myriad academic journals on precisely this topic since the dawn of this millennium! To write a book that takes a critical view of the business case for corporate social 
responsibility, it is necessary to draw from these previously published studies. How best to do so? I suppose I could gently paraphrase my prior work until the cows come home (say, $5 \mathrm{pm}$ ? When exactly do the cows get back to their places of residence?). But rather than test the boundaries of plagiarism, why not offer up the original source material? Unwisely sticking with the farm theme, why not get the details straight from the horse's mouth? Sure, some suggest that academic studies are to be found at the other end of the horse, but without question each article reprinted herein is an in-depth, (painfully) peer-reviewed, stand-alone case for some aspect of the argument I seek to make in this book. Why rephrase or relitigate each point when I can instead reproduce them?

If you're reading this, you probably have already seen or could easily gain access to most of the articles reprinted here. I'm saving you some hassle in that case. Here they are, all curated and cozy, in one place. But many haven't previously seen these articles and don't have ready access. Of more value, though, is that the articles in this book are organized and integrated to build a cohesive argument, rather than presented as independent pieces for readers to patch together on their own. In the remainder of this opening chapter, I will outline the overall argument and explain how each included reprint advances it.

This book also contains a concluding chapter filled with new material that makes a case for where we should go from here as scholars, practitioners, and society. That's right, this book is far more than old wine in a shiny new bottle, my dear reader! Though transparently selfserving to say so, I see this not as a book of reprints but as an original book with bonus supporting material. That makes it a bargain, even before I mention just how many ever-sharp Ginsu knives I'm willing to throw in to convince you to buy a copy or two today. Act now!

\section{Clarifying the case}

With the hard sell out of the way, let's get down to business on what this criticism of the business case is all about. The bottom line is that because the corporate bottom line is not firmly connected to corporate behavior, the business case does not motivate firms to consistently behave in socially responsible ways. And that's a shame, because the business case offers such an easy, win-win path to widespread corporate social responsibility; one in which there's no need for heavy-handed formal regulation. The argument is that if we just let the market have at it, firms will become more socially responsible as they doggedly pursue their own self-interest. After all, if they don't make nice, they know that they will suffer in the marketplace. Logically then, they will behave well. You may be familiar with Warren Buffett's famous quote: 'It takes 20 years to build a reputation and five minutes to ruin it. If you think about that, you'll do things differently.' Buffett has been one of the richest men in the world for more than 20 years based on investing in firms according to such logic, so this would seem to be sage business advice.

But how does the market actually enforce its discipline on firms? How is a firm's behavior linked to its financial performance? This is where stakeholders enter the picture. The market is not some soulless, shapeless monolith. It is composed of myriad sapient beings - stakeholders - who, by giving and rescinding their support, alter the standing of these firms. If a firm opens a daycare facility to ease the burden on working parents, it may be rewarded with increased loyalty from its current employees and improved recruitment yield from potential new employees. If a firm releases toxic pollutants into a stream, it may be punished by members of its community who block licenses for new facilities and by activists through protests and 
boycotts. The reputation and market value of the firm changes in accordance with changes in the favorability of the relationships the firm has with these and other stakeholders. I compare it to alchemy, a process by which a substance like lead magically transforms into gold. The stakeholder is the alchemical agent required for a firm's good acts to transform into something valuable to the firm; likewise, when a firm does something bad, it takes a stakeholder reaction to cause the firm to feel the pain of it.

Recognizing the role of stakeholders as the agents that make the business case work is an essential step forward. The next essential step is recognizing that stakeholders are fallible. Most of the time most stakeholders have no idea what is going on at most firms. Even were firms completely transparent, keeping track of everything exceeds anyone's bandwidth. Quick: what's going on right now at Walmart? K-mart? Motomart? Because stakeholders are fallible, the alchemical reaction required to turn corporate good into gold does not always complete; sometimes it fizzles or is inert, and sometimes it backfires. But when, and to what degree? That's what we are here to sort out. It cannot always pay to be good. If it did, then corporate social responsibility would be a money machine that enables enlightened firms to transform as much goodness as they can muster into as much profit as they can haul away. Money machines, like unicorns, Sasquatch, and ample on-campus parking, are of course mythical. To remain in the restrained realm of reality, where corns are multi, feet are mini, and parking spaces are scarce, we must explain how the process of transforming corporate good into gold really works, and clarify how it sometimes fails to work. Onward to the next section to see how these tasks are tackled in this book.

\section{Building and bounding the case}

Each of the reprints in this book sheds light on the mechanisms and limits of the business case. The reprints are organized into three sections. The first section introduces the business case by developing a conceptual model to explain how it pays to be good, then empirically demonstrates that financial returns indeed do accrue to good behavior. However, as first outlined in theory and then empirically validated, these returns vary based on a firm's history of responsibility, creating a curvilinear relationship between social and financial performance. The second section shifts analysis up a level to explain variation in the social performance of industries. A firm's performance, social and otherwise, is perceived relative to its peers. This interdependence can give rise to shared problems that require rival firms to work together, commonly through trade associations, though trade associations face difficulty in balancing the individual and shared interests of their member firms. The third section then turns to the implications of the dynamics discussed in the prior sections, arguing that stakeholders are often inattentive to firm behavior and rely on shortcuts to cope with their limited abilities, which only enlarges the void between how firms behave and how they are perceived, thereby bounding the business case.

\section{The arc of the business case}

In a special issue of Business and Society Review published in 2000, Charles Fombrun, Naomi Gardberg, and I (Chapter 2 in this volume) rang in the new millennium by explaining why firms spend their limited resources on 'doing good.' The question itself was far from novel even back then, but our take on it was new. We focused on the ways in which CSR (though corporate citizenship is the term we used) affects corporate reputation, rather than the common practice of looking at how it directly affects financial measures of 'doing well' such as stock 
market valuation and annual accounting returns. Our contention, an underlying theme that I will return to in the final reprint included in this book, was that social performance affects financial performance indirectly, via its effects on reputational capital.

Reputational capital is built by engaging in CSR and functions as a 'safety net' that buffers firms from reputational losses in times of crisis. Firms with good CSR practices get the benefit of the doubt from their stakeholders and so tend to suffer smaller losses and have quicker recoveries when things go wrong, relative to firms that have not accrued reputational capital. The reputational capital built through CSR also serves as an 'opportunity platform' on which myriad profitable opportunities may be built. Applying a novel real options perspective to CSR, we explained how the supportive stakeholder relationships associated with reputational capital create growth options that allow 'good' firms favorable access to future opportunities, whereas firms without such accrued goodwill lack the option to strike these deals.

This paper added depth to the established model of how doing good relates to doing well by addressing the intervening process and noting the bi-directional benefits of CSR. Moreover, it enriched understanding of variation in stakeholder action. The literature had tended to treat stakeholders as a monolith, but different stakeholders reward and punish firms in different ways. In this paper, we addressed the varying promises and threats to the firm from its relationships with investors, employees, partners, customers, regulators, communities, media, and activists. For example, employees offer the promise of commitment but the threat of rogue behaviour, while the media offer the promise of favorable coverage alongside the threat of exposure.

Our argument 'that corporate citizenship is a strategic tool that companies can use to manage reputational risk from stakeholder groups' caught on in academia, as indicated by this paper's high citation count. It has also been used to underpin consultant and media reports that argue, in broad strokes, for the value of CSR. However, a paper that I co-authored with Rob Salomon and published in Strategic Management Journal in 2006 (Chapter 3 in this volume) has probably had more influence on one specific aspect of the business case, that of socially responsible investing (SRI). SRI entails making investment choices on the basis of social performance. In the early 2000s, there were about 160 mutual funds and about a trillion dollars of total assets being managed on the basis of SRI. Those figures have grown massively since. Examples of SRI funds include Eventide Gilead, which is a Christian-based fund that avoids businesses that profit from abortion in any way, and the Vanguard FTSE Social Index, which excludes firms that are involved in alcohol, tobacco, pornography, military sales, and nuclear power, as well as those that do not have at least one woman on the board of directors, do not have an equal opportunity policy in place, have been subject to human rights violations, or have negative environmental impact.

While doctoral students, Rob and I teamed up to write a short book on the idiocy of SRI for an upstart publisher that a senior faculty member had vouched for. The publisher didn't survive long enough to allow us to complete our short book (and the senior faculty member retired soon after), but we didn't want our work to go to waste, so we analysed the data we had gathered and found a surprising result. Consistent with many SRI critics that had dismissed SRI funds as a dumb idea because limiting investment choices restricts earnings potential, we expected to find that SRI funds financially underperform non-SRI funds. And we did find this. But we also found that SRI funds outperformed non-SRI funds. That is, we found support for both opposing positions. Huh? 
Finance and accounting scholars had long been comparing the financial performance of SRI funds to non-SRI funds and finding mixed results. There is a great deal of variation in the screening intensity of SRI funds, though, and this variation was largely being ignored. Some SRI funds screen out a great many potential investments on the basis of their social performance, while others have much more porous screening criteria, so much so that their holdings resemble non-SRI funds. We reasoned that previous studies had found mixed results because they had muddled this range of screening intensity. When we accounted for screening intensity, we found a curvilinear relationship: those firms that screened the least and those that screened the most had the best financial performance, while those that screened a moderate amount were 'stuck in the middle,' earning the lowest financial returns.

Our findings suggested that it pays to be good, but also recognized that there are costs to being good; an important factor often overlooked in management scholarship on CSR. More intensely screening investments according to social performance criteria means ruling out more and more firms, industries, and sectors. As investment choices become more limited, a fund's ability to fully diversify becomes more constrained, causing it to bear unsystematic risk and thereby harming its risk-adjusted returns. This is why accounting and finance critics of SRI find it an inherently flawed approach to investing. However, while intense screening forces a smaller investment choice set, it may leave fund managers with a richer set of firms from which to make their investment choices. Screening more intensely can help SRI funds to eliminate risk-prone firms from their portfolios, thereby yielding a stronger and more stable set of stocks that earn higher risk-adjusted returns. Those funds that screen only moderately suffer the costs of loss of diversification but don't fully achieve the benefits of intense screening.

Our study was at the portfolio level and so did not directly address the firm-level relationship between social and financial performance, though. To dig directly into firm-level dynamics, in 2007 I published a paper in Academy of Management Review (Chapter 4 in this volume) that developed the concept of stakeholder influence capacity (SIC). Think of SIC like this: someone who has always been a jerk to you for as long as you've known them is now walking up to you, smiling, saying flattering things, and handing you a fragrant bouquet of beautiful flowers and a huge box of fine chocolates. What's your reaction? You're probably skeptical, since it's out of character. Though they've gone to all this trouble, they are unlikely to gain your favor. In fact, you may suspect they're up to no good, so it could backfire.

It's like this with firms, too. Stakeholders view CSR through the prism of history. Without a history of relevant CSR, a sudden good act, no matter how nice, is likely to be viewed with a healthy dose of skepticism by stakeholders. In contrast, a firm with a history of good deeds has the capacity to favorably influence its stakeholders with a similar act. Imagine that McDonald's has made a sizeable contribution to the American Heart Association, a non-profit organization that fights heart disease. Would you interpret this differently than Subway's equivalent contribution to the same organization? What if Fatburger or The Heart Attack Grill took on this same charitable cause? Because history matters to how acts of CSR are interpreted, even the same firm can provoke different stakeholder responses to the same act at different points in time. Imagine the difference in reactions if Union Carbide had donated $\$ 10$ million to a hospital in Bhopal, India, prior to its deadly poison gas leak that killed thousands there in 1984 , versus after. 
Developing the concept of SIC and clarifying how it influences returns to CSR helped to push the literature past its decades-long quest to prove that it either does or does not pay to be good. Different firms receive different returns from different acts of CSR because they have different histories. Rather than continuing to battle, with increasingly complex data sets and methods, over whether or not it universally pays to be good, the conversation could instead shift to sorting out the contingencies that determine whether or not a specific act of CSR pays for a given firm at a particular point in time.

In a paper published in Strategic Management Journal in 2012 (Chapter 5 in this volume), Rob Salomon and I teamed up again (now as faculty members!), this time to empirically validate that a firm's history affects the degree to which it profits from CSR. We again compared contrasting perspectives on the relationship between social and financial performance and determined the net result by accounting for both the costs and benefits of CSR. However, this time we focused directly on firms, not funds. To become more and more socially responsible, a firm must allocate more and more of its limited resources toward CSR. Whether it be philanthropy, pollution abatement, employee benefits, community volunteering, or some other good act, doing more of it requires more resources, to include time, attention, and money. If CSR were costless, then there would be no need to debate its business merits. But it is costly, so as a firm engages in more CSR, its costs necessarily rise and, all else equal, its financial performance must decline.

Of course, all else is never equal. As a firm engages in more CSR, it improves its stakeholder relationships, which helps the firm to garner resources on more favorable terms, as well as safeguard its downside risk. What is the net result of these two opposing forces on the bottom line? Do the benefits fully negate the costs and thereby net insignificant or neutral returns from CSR? Or do the costs from CSR exceed accrued benefits, or vice versa? If SIC functions as previously advertised, then the net result should be ... drumroll please ... a curvilinear relationship. And indeed, that is what we found.

Those firms with a weak history of being good get little back from any CSR investments they might make because they lack SIC. For each dollar they invest in CSR, they should expect to lose nearly all of it because their good acts are not credible. More CSR thus means more losses for those firms with little SIC. This creates the downward portion of a U-shaped curve. However, as they continue to engage in acts of CSR, firms accrue SIC, so the amount they lose on each invested dollar declines, causing the U-shape to bottom out. Eventually, with enough of a record of ongoing CSR investment, the firm gains SIC ample to profit from further CSR. Thereafter, a dollar invested in CSR returns not a loss but a gain. More CSR thus means more profit, creating the upward-sloping side of the U-shape. In sum, it pays to be good, but only if you're good enough. If you aren't going to be really good, then staying relatively bad is more likely to maximize your financial returns because it limits the costs associated with engaging in CSR. What doesn't pay is to be a 'sorta nice guy' who suffers much of the cost of being nice yet does not go far enough to gain the offsetting benefits of being distinguished as a nice guy.

Overall, these four studies portray the business case as a moderated process with stakeholders at the center. Stakeholders determine which acts of CSR are rewarded, as well as which acts of irresponsibility are punished, and they are swayed in their assessments by firm history, which helps to explain variation in returns to CSR. However, firm history is not the only contingency to consider when mapping the contours of the business case. A stakeholder's 
perception of a particular firm at a particular point in time is shaped by the behaviors of similar other firms. For example, though you may know little about the activities of DTE Energy Company, you may be very familiar with activities at other firms in its industry such as those at Three Mile Island, Chernobyl, and Fukishima, and on that basis form a view of DTE. Stakeholders view a firm through the prism of not just its own history, but also that of its industry. I next shift the discussion to the industry level to view the business case from this vantage point.

\section{Industry matters}

Also around the turn of the millennium, I began working with Andy King and Mike Lenox, who were on the faculty at NYU at the time. Funded in part by an Environmental Protection Agency grant, their Business \& Environment at Stern (BES) research group sought to explain how industry self-regulation (ISR) affects corporate environmental performance. I brought my expertise in corporate reputation to bear on this issue and together, as spelled out in the chapter we published in 2002 in the edited book, Organizations, Policy, and the Natural Environment (Chapter 6 in this volume), we developed strategic solutions to 'reputation commons problems' (RCP).

A commons is a shared space. As most anyone who has used a public bathroom can attest, a commons can be problematic to maintain. Economic logic dictates that overuse will occur, causing the commons to collapse unless some centralized authority arises to govern it or it is parceled out for private ownership. Examples of over-grazed public lands, over-fished public waterways, and over-felled public forests abound.

We pushed the concept beyond the realm of physical space in characterizing an industry's reputation as a commons. When stakeholders cannot or do not distinguish one firm's actions from those of similar others, reputation commons arise. Reputation commons need not be problematic; a firm can benefit from improvements to its industry's reputation that are brought about by the good behaviors of rival firms. A reputation commons becomes a problem, though, when stakeholders punish an industry broadly for the misconduct of one or a few firms within it. We reasoned that when such problems arise, firms seek solutions that lessen their exposure to these spillovers either by reducing the threat of stakeholder sanction or 'privatizing' the reputation commons. ISR initiatives are the organizational structures through which industries often try to implement these solutions. But do they work?

Drawing on my dissertation work, Andy King and I published a paper in Academy of Management Journal in 2008 (Chapter 7 in this volume) in which we empirically tested the functionality of ISR as a solution to RCPs. The chemical industry formed a sort of natural experiment for this. In late 1984, a Union Carbide facility in Bhopal, India, leaked toxic gas that killed thousands. Thereafter, the entire chemical industry suffered severe reputational damage and faced louder calls for much more extensive formal regulation each time more minor chemical spills and leaks occurred at any facility. It became increasingly difficult for firms to gain and retain licenses to operate their plants in many communities. To decrease the risk that another accident would cripple the industry as a whole, the industry's main trade association created an ISR initiative called Responsible Care (RC). We tested whether or not $\mathrm{RC}$ was able to mitigate this RCP.

Picture an RCP as ripples spreading across a pond after something disturbs the calm. If you're floating on that pond, a gentle ripple from a pebble is no problem. However, a major 
shock wave from a boulder being tossed in may sink you. To determine the effectiveness of the RC program, we compared the spread of disturbances before and after its implementation and found that $\mathrm{RC}$ was indeed effective in calming the waters of the chemical industry, turning future disturbances from shock waves back into gentle ripples. But how? Well, that's really the more interesting part of the paper. Our analysis suggests that it worked by building 'mental fences' in the minds of stakeholders that helped them to individualize firm behavior. When firms 'fence in' their own problems, they mitigate the collective risk that another firm's problem will spread beyond its borders and cause harm to rivals. We discussed how the stakeholder relationship management programs that were central to RC built and maintained these mental fences, helping firms to be judged on their own merits rather than tarred by the same brush as their rivals.

As the RC program demonstrated, rival firms can sometimes come together to resolve shared problems. However, maintaining this cooperation over time is difficult. Each firm faces a balancing act in allocating its limited resources to the industry's efforts while still furthering its individual interests. In a paper published in Journal of Management Studies in 2006 (Chapter 8 in this volume), I took on the problem of how firms find their working balance between competitive and what I termed communal strategy. Communal strategy refers to a given firm's contributions to efforts to manage the shared interests of their industry, as contrasted with competitive strategy by which a firm seeks to stand apart from its rivals. Put another way, through communal strategy firms seek to influence the 'industry effect,' and through competitive strategy they seek to influence the 'firm effect.' Both factors drive firm performance, but they compete for the firm's limited resources. I established a framework that explains how the dynamics of an organizational field can make industry effects 'matter' more or less to firm performance over time, thereby altering a firm's incentive to divert resources from competitive strategy and toward communal strategy. When they perceive industry effects to impinge on their reputation and financial performance, firms shift resources to communal strategy, at least for long enough to improve industry effects, but once the shared problem is resolved, the balance shifts back to competitive strategy.

Firms typically engage in communal strategy through the organizational structure of a trade association. There are thousands of trade associations representing the interests of almost every industry, from advertising to wine and everything in between. By coordinating the resources and uniting the voices of member firms, trade associations can have major impacts on governmental policy, social welfare, and of course industry performance. Yet we know little about them. The few management studies have focused primarily on population dynamics, noting the conditions under which trade associations tend to be founded, merge, or disband. However, there is a great deal of variation in the activity of trade associations. Some are virtually inert while others accrue massive resources and a great deal of internal and external influence. What explains this variation?

In a paper published in Business \& Society in 2013 (Chapter 9 in this volume), I measured changes in trade association activity. Based on the balancing framework described previously, I expected to find that firms would shift resources to increase their investment in trade association activity during times of industry-wide trouble. But when I tested this assumption on a set of 148 major industry trade associations over time, I found that increases in trade association spending were not related to industry-wide downturns. Instead, decreases in the profitability of the four largest firms in their industries drove increases in the spending of trade 
associations. This suggests that the interests of large firms drive trade association agendas. Thus, it is necessary to attend to the balancing act between competitive and communal strategy even within communal organizations.

As the studies in this section collectively pointed out, to stakeholders trying to make sense of CSR and to firms trying to manage their relationships with these stakeholders, industry matters. The reputation of an industry is a sort of commons that is difficult to maintain, and if not collectively well-managed can lead stakeholders to punish many firms for the irresponsibility of one or a few firms. This reputational interdependence occurs because stakeholders are unable to parse and make sense of the myriad individual behaviors of voluminous individual firms. The next section digs more deeply into the nature and implications of stakeholder cognitive constraints.

\section{Assessing the assessors}

If you happen across someone from Star-Kist casually harpooning a whale or someone from Purina gleefully kicking a puppy, you may say something or even do something about it, to include altering your seafood and dogfood purchasing habits, and perhaps much more. But you'll never see much of what most firms do, especially the bad stuff. Firms obviously have incentive to hide the bad stuff rather than publicize it as they do their good acts. Even if they put it on a pedestal, though, or as is more likely, media outlets report on it, most stakeholders are unlikely to be aware of most of what most firms do.

Stakeholders can attend to only a small portion of what firms do. They're human. Nonetheless, much of the research on how stakeholders respond to firm misconduct starts from the premise that stakeholders are aware of specific acts. In a paper published in Journal of Management in 2014 (Chapter 10 in this volume), I challenge this assumption. I describe stakeholder action not as a singular decision point (Do I punish this firm or not for what it did?), but as the result of a probabilistic multi-stage cognitive process. Characteristics of individual stakeholders and the situations in which a given act occurs affect the likelihood that a stakeholder will first notice a particular act of misconduct, as well as how they make sense of it, before finally affecting whether and how they decide to respond. Stakeholders may not notice a given act, or if they notice it, they may give a firm the benefit of the doubt, or even if they do notice and deem it misconduct, they may choose to do nothing about it. This combination of steps explains why firms often fail to 'feel the pain' of stakeholder backlash in response to their bad acts. It's not just that stakeholders are often unwilling to take on the burden of punishing firms, but more so, that many bad acts are filtered out before stakeholders face this decision point.

As Sohvi Leih and I showed in a paper published in Business \& Society in 2018 (Chapter 11 in this volume), cognitive constraints affect not only how stakeholders deal with firm misconduct but how they deal with firm behavior in general. Lacking the ability to directly observe what is going on at all firms at all times, stakeholders rely on intermediaries for information about firm behavior. Media outlets have been quick to capitalize on this need. Those of us in universities and business schools especially can attest that rankings of the qualities of various organizations abound nowadays from nearly every corner of the media world, from Businessweek to US News \& World Report. These rankings have proven to be highly influential, guiding major decisions such as what to buy, where to attend college, where 
to work, and whom to deem Sexiest Man Alive in any given year (no, I'm not bitter; I'm holding my breath and toning my abs for 2027).

We sought to better understand how people use media rankings to assess firms, particularly in comparison to other information they may have about these firms. In an experimental study, we found, as expected, that rankings did shape what people thought about firms. But there is some nuance. This influence was strongest when the ranking was congruent with other information one had about the firm and this other information was negative. However, if one was already aware of negative information about a firm, seeing a favorable ranking had little influence on assessment. People are loathe to challenge their established beliefs, instead discounting or ignoring disconfirming information. Reputations can thus be sticky. It seems that Warren Buffett may have overstated the case for reputational fragility, as firms can rest on their laurels for a while before reputation catches up to reality. In consonance with Buffett's logic, though, this also suggests that it is harder to fix a damaged reputation than it is to maintain it.

Clearly the link between how a firm behaves and how its stakeholders relate to it is a loose one. But as I point out in a paper that is to be published in Business \& Society in 2019 (Chapter 12 in this volume), the link between firm behavior and social welfare may be outright broken, and that's the link we are really concerned with. Over time, the literature has confused attending to stakeholders with attending to the needs of society. Sure, managing a firm to be responsive to the demands of its stakeholders is an important step forward from the days of firms focusing solely on shareholder issues. However, prioritizing the allocation of a firm's limited resources according to stakeholder power, as the business case prescribes, is unlikely to guide firms toward tackling many of society's pressing problems. CSR stands for corporate social responsibility, not critical stakeholder responsiveness. Those in society who struggle the most are least likely to have power adequate to garner priority from firms seeking to more efficiently allocate their scarce resources to keep their myriad stakeholders satisfied. Thus, as the business case guides firms to focus on actions that maintain and improve stakeholder relations, it seems to also be guiding firms away from involvement in many important social issues.

\section{Closing the current case}

Corporations have come a long way since child labor, labor camps, black lung, open pollution, and so on were commonplace. But they still have a long way to go, and the studies discussed above and reproduced in the pages to follow suggest that the business case for corporate social responsibility will not get us much farther. The disconnect or at least lag between a firm's actions and the response of its stakeholders is problematic for the business case. If its good acts don't seem to bring about stakeholder favor, then a firm may see no merit in doing more good things. Even worse, if its bad acts don't seem to bring about stakeholder disfavor, then a firm may see no reason to stop being bad. Sure, as the business case currently stands, lots of firms are still motivated to do lots of nice, responsible things like giving employees paid vacations and providing philanthropic support to their communities. But lots of firms continue to do lots of irresponsible things, and huge social problems like climate change and poverty remain and worsen.

Can we do better? The final chapter of this book sets the stage for future research on the business case for corporate social responsibility, calling for more research on the cognitive 
mechanisms that underpin the business case, outlining the need for government intervention to fill gaps where market solutions fail, and pushing extant theoretical perspectives into the digital age. Since I predicted earlier that it'll be 2027 before People magazine recognizes my superficial merits, and it may take longer for the Nobel committee to get around to rewarding my scholarly merits, I suppose I have no choice but to remain cautiously optimistic that together we will find a viable way forward in the coming years. 